\title{
Photoluminescence studies of impurity transitions in Mg-doped AIGaN alloys
}

\author{
M. L. Nakarmi, ${ }^{1, a)}$ N. Nepal, ${ }^{2}$ J. Y. Lin, ${ }^{2}$ and H. X. Jiang ${ }^{2}$ \\ ${ }^{1}$ Department of Physics, Brooklyn College of the City University of New York, Brooklyn, \\ New York 11210, USA \\ ${ }^{2}$ Department of Physics, Kansas State University, Manhattan, Kansas 66506-2601, USA
}

(Received 17 October 2008; accepted 13 February 2009; published online 4 March 2009)

\begin{abstract}
Deep ultraviolet photoluminescence spectroscopy was employed to study the impurity transitions in Mg-doped AlGaN alloys. A group of deep level impurity transitions was observed in $\mathrm{Mg}$-doped $\mathrm{Al}_{x} \mathrm{Ga}_{1-x} \mathrm{~N}$ alloys, which was identified to have the same origin as the previously reported blue line at $2.8 \mathrm{eV}$ in $\mathrm{Mg}$-doped $\mathrm{GaN}$ and was assigned to the recombination of electrons bound to the nitrogen vacancy with three positive charges $\left(V_{\mathrm{N}}{ }^{3+}\right)$ and neutral $\mathrm{Mg}$ acceptors. Based on the measured activation energies of the $\mathrm{Mg}$ acceptors in $\mathrm{AlGaN}$ and the observed impurity emission peaks, the $V_{\mathrm{N}}{ }^{3+}$ energy levels in $\mathrm{Al}_{x} \mathrm{Ga}_{1-x} \mathrm{~N}$ have been deduced for the entire alloy range. It is demonstrated that the presence of high density of $V_{\mathrm{N}}{ }^{3+}$ deep donors translates to the reduced $p$-type conductivity in AlGaN alloys due to their ability for capturing free holes. (c) 2009 American Institute of Physics. [DOI: 10.1063/1.3094754]
\end{abstract}

AlGaN alloys have attracted much attention due to their promising applications in areas of chip-scale ultraviolet (UV) and deep UV optoelectronic devices in the spectral range down to $200 \mathrm{~nm}$. The operation of $\mathrm{AlGaN}$ based deep UV light emitting diodes (LEDs) with milliwatts optical power output at around $280 \mathrm{~nm}$ has been successfully demonstrated. $^{1-4}$ The availability of AlGaN semiconductor based UV emitters opens up important applications in areas of biochemical agent detection, general lighting, as well as new opportunities for medical and health research. It is the recent advances in material growth, conductivity control, and device processing of $\mathrm{Al}$-rich $\mathrm{AlGaN}$ alloys that made it possible to fabricate operational AlGaN based deep UV LEDs. Recently AlN based LEDs and detectors have also been demonstrated. ${ }^{5,6}$ Although tremendous progress has been made in the development of AlGaN alloys and their applications in deep UV devices, achieving $p$-type conductivity in Al-rich AlGaN alloys is still highly challenging. Very few studies have been reported on $p$-type doping of AlGaN alloys or bulk materials. ${ }^{7-15}$ The main reasons of difficulty to achieve $p$-type conductivity are the large activation energy of the magnesium $(\mathrm{Mg})$ acceptors and strong compensation effects due to the presence of intrinsic defects. Activation energy of $\mathrm{Mg}$ acceptors in $\mathrm{GaN}$ is about $160 \mathrm{meV}$, and it increases with increasing $\mathrm{Al}$ content in AlGaN alloys. For AlN, the reported $\mathrm{Mg}$ activation energies are in the range $0.5-0.6 \mathrm{eV} .^{5,16,17}$ The compensating defects in Mg-doped AlGaN alloys are believed to be nitrogen vacancies. 18,19

In this letter, we report on the growth and photoluminescence (PL) studies of impurity transitions in $\mathrm{Mg}$-doped $\mathrm{Al}_{x} \mathrm{Ga}_{1-x} \mathrm{~N}$ alloys for $x$ ranging from 0 to 1 . Mg-doped $\mathrm{Al}_{x} \mathrm{Ga}_{1-x} \mathrm{~N}$ alloys were grown on $c$-plane (0001) sapphire substrates by metal-organic chemical vapor deposition (MOCVD). Samples with different Al content $(x)$ were grown with $\mathrm{x}$ ranging from $0(\mathrm{GaN})$ to 1 (AlN). Trimethylgallium and trimethylaluminum were used as gallium and aluminum sources, respectively. Blue ammonia was used

${ }^{a)}$ Electronic mail: mlnakarmi@brooklyn.cuny.edu. as the nitrogen source. For magnesium doping, biscyclopentadienyl-magnessium was transported into the reactor. Secondary ion mass spectroscopy (SIMS) measurements were performed for selective samples to confirm the targeted $\mathrm{Mg}$ concentrations in the samples. Deep UV PL spectroscopy was employed to study the optical transitions in the $\mathrm{Mg}$ doped AlGaN alloys. The PL system consists of a frequency quadrupled $100 \mathrm{fs}$ Ti:sapphire laser with an excitation wavelength of $197 \mathrm{~nm}$ (with an average power of about $3 \mathrm{~mW}$ and a repetition rate of $76 \mathrm{MHz}$ ), a monochromator $(1.3 \mathrm{~m})$ with a detection capability ranging from 185 to $800 \mathrm{~nm}$ and a streak camera with a time resolution of $2 \mathrm{ps}$.

Figure 1 shows the low temperature $(10 \mathrm{~K}) \mathrm{PL}$ spectra of $\mathrm{Mg}$-doped $\mathrm{Al}_{x} \mathrm{Ga}_{1-x} \mathrm{~N}$ alloys of varying $x(0,0.3,0.55$, $0.7,0.8$, and 1.0). In all samples, a group of impurity transitions, which are highlighted by the bold arrows, is dominant over that of the band edge. The spectral peak positions of this group of impurity transitions are blueshifted from $2.81 \mathrm{eV}$ in $\mathrm{GaN}$ to $4.7 \mathrm{eV}$ in AlN. For Mg-doped AlN, a weak $I_{1}$ (exciton bound to neutral $\mathrm{Mg}$ ) emission peak at $6.02 \mathrm{eV}$ and an additional impurity peak at $5.55 \mathrm{eV}$ are evident. The emission peak at $5.55 \mathrm{eV}$ is attributed to the transition of electrons in the conduction band (or bound to shallow donors) to neutral $\mathrm{Mg}$ acceptors. ${ }^{17}$ This assignment provides an energy level of $\mathrm{Mg}$ acceptors in $\mathrm{AlN}$ of about $0.5 \mathrm{eV}$, which is consistent with previously reported results. ${ }^{16,17}$ The emission peaks at about 4.96 and $5.31 \mathrm{eV}$ in $\mathrm{Al}_{x} \mathrm{Ga}_{1-x} \mathrm{~N}$ with $x=0.7$ and 0.8 are of the same origin as the $5.55 \mathrm{eV}$ line in AlN.

The PL spectral peak position $\left(E_{\mathrm{emi}}\right)$ of the highlighted group of impurity transitions in $\mathrm{Al}_{x} \mathrm{Ga}_{1-x} \mathrm{~N}$, as illustrated in inset of Fig. 1, increases almost linearly with increasing the $\mathrm{Al}$ content $(x)$. Although an increase in $E_{\text {emi }}$ is expected from the energy bandgap increase with $x$, the linear variation indicates that these impurity transitions are of the same physical origin. Although there is a debate concerning the origin of the $2.8 \mathrm{eV}$ emission peak in $\mathrm{Mg}$-doped $\mathrm{GaN}$, various investigations support the model of a donor acceptor pair (DAP) transition involving a deep donor and $\mathrm{Mg}$ acceptor. $^{20-25}$ The inset of Fig. 2 shows the representative 


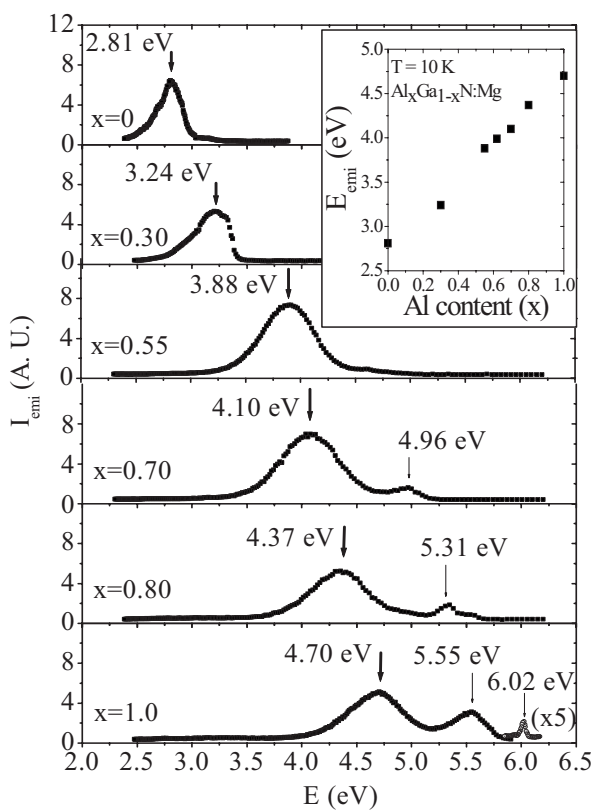

FIG. 1. Low temperature $(10 \mathrm{~K}) \mathrm{PL}$ spectra of $\mathrm{Mg}$-doped $\mathrm{Al}_{x} \mathrm{Ga}_{1-x} \mathrm{~N}$ alloys with varying $\mathrm{Al}$ contents $(x)$ from 0 to 1 . A group of impurity transitions, which are highlighted by the bold arrows, is dominant over that of the band edge. Inset shows the PL emission peak position $\left(E_{\text {imp }}\right)$ of the group of deep impurity transitions in $\mathrm{Al}_{x} \mathrm{Ga}_{1-x} \mathrm{~N}$ alloys (highlighted by the bold arrows in Fig. 1) as a function of the $\mathrm{Al}$ content $(x)$

SIMS profiles of Mg levels in $\mathrm{Al}_{x} \mathrm{Ga}_{1-x} \mathrm{~N}$ ( $x=0.7$ and 1). The $\mathrm{Mg}$ levels in these samples are in the order of $10^{20} \mathrm{~cm}^{-3}$. Figure 2 shows the representative temporal response, which was measured for the emission peak at $4.7 \mathrm{eV}$ measured in AlN at $10 \mathrm{~K}$. The long decay lifetime $\tau(>1 \mu \mathrm{s})$ is consistent with the reported temporal response measurements in $\mathrm{GaN} .{ }^{23}$ The measured long decay lifetime of these transitions supports the assignment of a DAP type of transition involving a deep donor and neutral $\mathrm{Mg}$ acceptor, consistent with the physical origin of the $2.8 \mathrm{eV}$ blue line in $\mathrm{Mg}$-doped $\mathrm{GaN}$ (Refs. 20-25) and the $4.7 \mathrm{eV}$ line in Mg-doped AlN. ${ }^{16,17}$

The formation energies $\left(E_{f}\right)$ of various native defects in $\mathrm{GaN}$ and AlN have been previously calculated. ${ }^{18,19}$ In "p-type" materials [having Fermi energy $\left(E_{F}\right)$ near the valence band], the nitrogen vacancies $\left(V_{\mathrm{N}}\right)$ were predicated to

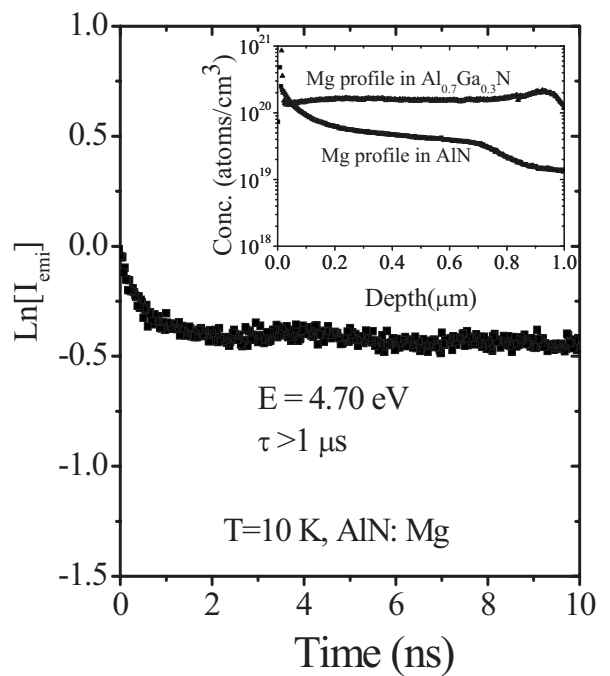

FIG. 2. Lifetime of $4.7 \mathrm{eV}$ peak in AlN. Long decay lifetime ( $>1 \mu \mathrm{s})$ indicating a DAP type transition. Inset shows the SIMS profile of Mg levels in $\mathrm{Al}_{0.7} \mathrm{Ga}_{0.3} \mathrm{~N}$ and AlN. $\mathrm{Mg}$ level is in the order of $10^{20} \mathrm{~cm}^{-3}$.

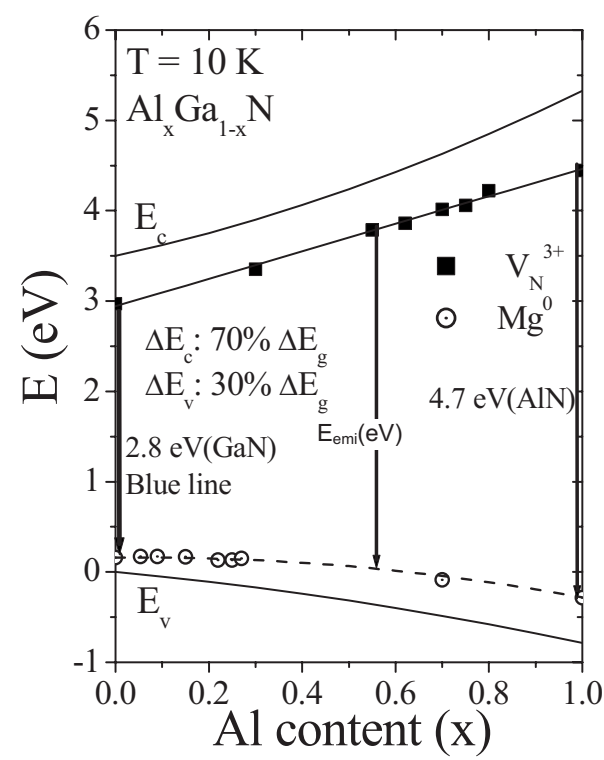

FIG. 3. The nitrogen vacancy $\left(V_{\mathrm{N}}{ }^{3+}\right)$ and $\mathrm{Mg}$ acceptor energy levels in $\mathrm{Al}_{x} \mathrm{Ga}_{1-x} \mathrm{~N}$ alloys as functions of $x$. The conduction and valence band offsets of the AlGaN alloys system are taken to be $70 \%$ and $30 \%$, respectively. The valence band maximum of $\mathrm{GaN}$ is taken as $E=0$.

have low formation energies in $\mathrm{GaN}$ and AlN. Moreover, the nitrogen vacancy with triple positive charges $\left(V_{\mathrm{N}}^{3+}\right)$ has smaller formation energy than those with a single positive charge $\left(V_{\mathrm{N}}{ }^{1+}\right)$, while $V_{\mathrm{N}}^{2+}$ is unstable. Thus, the theoretical calculations suggested that the generation of $V_{\mathrm{N}}{ }^{3+}$ is more favorable during the growth of Mg-doped AlGaN alloys. The energy level of $V_{\mathrm{N}}{ }^{1+}$ is shallower than $V_{\mathrm{N}}{ }^{3+}$, and the observed emission lines are not consistent with the presumed transitions involving $V_{\mathrm{N}}{ }^{1+}$ and $\mathrm{Mg}$ acceptors. Further, the observed impurity transitions are completely different from the impurity transitions in $n$-type AlGaN alloys. ${ }^{26,27}$ Thus we assign the observed impurity emissions are related to the transitions of electrons bound to $V_{\mathrm{N}}{ }^{3+}$ to $\mathrm{Mg}$ acceptors.

To provide a more comprehensive picture of the nitrogen vacancy levels in AlGaN alloys, we have plotted the alloy composition dependence of the conduction band edge $\left(E_{c}\right)$ and valence band edge $\left(E_{v}\right), \mathrm{Mg}$ level, and $V_{\mathrm{N}}{ }^{3+}$ level in $\mathrm{Al}_{x} \mathrm{Ga}_{1-x} \mathrm{~N}$ alloys, as shown in Fig. 3. In obtaining Fig. 3, we have used the $\mathrm{Al}_{x} \mathrm{Ga}_{1-x} \mathrm{~N}$ bandgap variation, $E_{g}(x)$ $=(1-x) E_{g}(\mathrm{GaN})+x E_{g}(\mathrm{AlN})-b x(1-x)$ with the bowing parameter $b=1 \mathrm{eV}$. The energy gaps of $\mathrm{GaN}$ and AlN were taken as 3.50 and $6.11 \mathrm{eV}$ at $10 \mathrm{~K}$ and the band offset of the $\mathrm{AlGaN}$ alloy system was taken as $70 \%(30 \%)$ for the conduction (valence) band. The valence band maximum of $\mathrm{GaN}$ was chosen as $E=0$. The $\mathrm{Mg}$ acceptor levels in $\mathrm{Al}_{x} \mathrm{Ga}_{1-x} \mathrm{~N}$ alloys for various $x$ are taken from the published reports including our previous works and summarized in Table $\mathrm{I}^{4,9,11,16,17}$ Based on these results, the variation of the $\mathrm{Mg}$ energy level with $x$ has been traced. From the Mg acceptor energy levels $E_{A}(x)$ and the observed impurity emission peaks $E_{\text {emi }}(x)$, the energy levels of $V_{\mathrm{N}}{ }^{3+}$ in $\mathrm{Al}_{x} \mathrm{Ga}_{1-x} \mathrm{~N}$ alloys as a function of $x$ can be written as

$$
E_{V_{\mathrm{N}}^{3+}}(x)=E_{g}(x)-E_{\mathrm{emi}}(x)-E_{A}(x)+E_{V} .
$$

The Coulomb interaction term between ionized donors and acceptors has been neglected in the calculation. Here, $E_{v}=-0.3 \Delta E_{g}(x)$. The three arrows drawn from the $V_{\mathrm{N}}{ }^{3+}$ level to the neutral $\mathrm{Mg}$ acceptor level represent the impurity emis- 
TABLE I. Mg acceptor energy levels in $\mathrm{Al}_{x} \mathrm{Ga}_{1-x} \mathrm{~N}$ alloys.

\begin{tabular}{lccccccccc}
\hline \hline Al content $(x)$ & 0 & 0.054 & 0.09 & 0.15 & 0.22 & 0.25 & 0.27 & 0.7 & 1 \\
Mg acceptor energy level & 0.16 & 0.209 & 0.220 & 0.250 & 0.262 & 0.279 & 0.311 & 0.4 & 0.5 \\
$E_{A}(x)(\mathrm{eV})$ & & \multicolumn{2}{c}{9} & & & 11 & & 4 & 16,17 \\
References & & & & & & & & &
\end{tabular}

sion energy peak positions in $\mathrm{GaN}, \mathrm{AlGaN}$, and AlN. From Fig. 3, we obtain energy levels of $V_{\mathrm{N}}{ }^{3+}$ of about $0.53 \mathrm{eV}$ in $\mathrm{GaN}$ and $0.88 \mathrm{eV}$ in AlN. Calculated energy level of $V_{\mathrm{N}}{ }^{3+}$ is in the range of $0.4-0.59 \mathrm{eV}$ in $\mathrm{GaN}$ and that of $0.9-1.1 \mathrm{eV}$ in AlN. ${ }^{19,28}$ Hence the energy levels of $V_{\mathrm{N}}{ }^{3+}$ obtained here experimentally for GaN and AlN agree reasonably well with the previous calculations.

By minimizing the impurity transitions associated with $V_{\mathrm{N}}{ }^{3+}$, we have been able to improve the quality and conductivity of $\mathrm{Mg}$ doped $\mathrm{Al}$-rich $\mathrm{AlGaN}$ alloys. This was done by changing the growth conditions especially by increasing V/III ratio as demonstrated by the results presented in Fig. 4 for two Mg-doped $\mathrm{Al}_{x} \mathrm{Ga}_{1-x} \mathrm{~N}$ alloys $(x \sim 0.7)$ samples. Figure 4(a) shows the room temperature PL spectrum of a sample that has the dominant $V_{\mathrm{N}}{ }^{3+}$ related emission peak at about $4.2 \mathrm{eV}$. The sample is highly insulating. By increasing the V/III ratio from 2000 to 5000, we were able to significantly suppress the emission intensity of the $V_{\mathrm{N}}{ }^{3+}$ related transition and concomitantly achieved an enhancement in $p$-type conductivity for the sample shown in Fig. 4(b). We observed the reduced emission intensity of the $V_{\mathrm{N}}{ }^{3+}$ related transition always translates into improved $p$-type conductivity in Mg-doped AlGaN alloys. This clearly shows that the observed impurity transitions are related to the hole compensating centers.

In summary, deep UV PL spectroscopy was employed to study the impurity transitions in $\mathrm{Mg}$-doped $\mathrm{Al}_{x} \mathrm{Ga}_{1-x} \mathrm{~N}$ alloys $(0 \leqslant x \leqslant 1)$ grown on sapphire substrates by MOCVD. A group of impurity transitions of similar nature was observed.

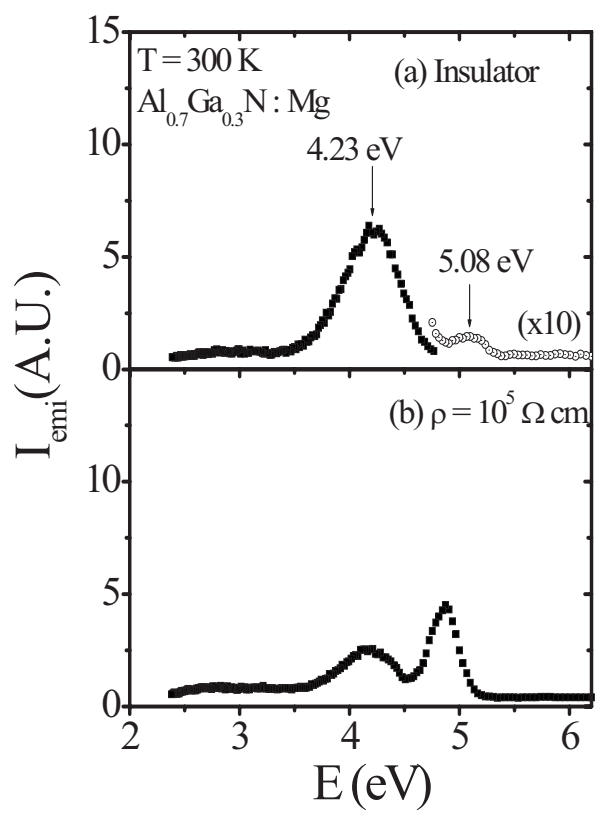

FIG. 4. Comparison of PL spectra of Mg-doped $\mathrm{Al}_{0.7} \mathrm{Ga}_{0.3} \mathrm{~N}$ alloys. The epilayer in (a) is highly resistive, while the epilayer in (b) has a resistivity of $\sim 10^{5} \Omega \mathrm{cm}$ at room temperature and exhibits $p$-type at elevated temperatures (with a $p$-type resistivity of $40 \Omega \mathrm{cm} 800 \mathrm{~K}$ ).
The transitions were assigned to the recombination of electrons bound to triply charged nitrogen vacancies $\left(V_{\mathrm{N}}^{3+}\right)$ and the neutral $\mathrm{Mg}$ acceptors. The variation of the energy level of the nitrogen vacancies with three positive charges $\left(V_{\mathrm{N}}{ }^{3+}\right)$ in $\mathrm{Al}_{x} \mathrm{Ga}_{1-x} \mathrm{~N}$ alloys with the $\mathrm{Al}$ content $(x)$ has been deduced from the energy levels of $\mathrm{Mg}$ acceptors and the observed PL impurity emission peaks. The deduced energy levels are consistent with the previous calculations.

The research is supported by ARO and NSF.

${ }^{1}$ K. Mayes, A. Yasan, R. McClintock, D. Shiell, S. R. Darvish, P. Kung, and M. Razeghi, Appl. Phys. Lett. 84, 1046 (2004).

${ }^{2}$ J. P. Zhang, X. Hu, Yu. Bilenko, J. Deng, A. Lunev, M. S. Shur, R. Gaska, M. Shatalov, J. W. Yang, and M. A. Khan, Appl. Phys. Lett. 85, 5532 (2004)

${ }^{3}$ A. J. Fischer, A. A. Allerman, M. H. Crawford, K. H. A. Bogart, S. R. Lee, R. J. Kaplar, and W. W. Chow, Proc. SPIE 5530, 38 (2004)

${ }^{4}$ M. L. Nakarmi, K. H. Kim, M. Khizar, Z. Y. Fan, J. Y. Lin, and H. X. Jiang, Appl. Phys. Lett. 86, 092108 (2005).

${ }^{5}$ Y. Taniyasu, M. Kasu, and T. Makimoto, Nature (London) 441, 325 (2006).

${ }^{6}$ J. Li, Z. Y. Fan, R. Dahal, M. L. Nakarmi, J. Y. Lin, and H. X. Jiang, Appl. Phys. Lett. 89, 213510 (2006).

${ }^{7}$ T. Tanaka, A. Watanabe, H. Amano, Y. Kobayashi, I. Akasaki, S. Yamazaki, and M. Koike, Appl. Phys. Lett. 65, 593 (1994).

${ }^{8}$ I. Akasaki and H. Amano, Mater. Res. Soc. Symp. Proc. 242, 383 (1991).

${ }^{9}$ M. Suzuki, J. Nishio, M. Onomura, and C. Hongo, J. Cryst. Growth 189, 511 (1998).

${ }^{10}$ L. Sugiura, M. Suzuki, J. Nishio, K. Itaya, Y. Kokubun, and M. Ishikawa, Jpn. J. Appl. Phys., Part 1 37, 3878 (1998).

${ }^{11}$ J. Li, T. N. Oder, M. L. Nakarmi, J. Y. Lin, and H. X. Jiang, Appl. Phys. Lett. 80, 1210 (2002).

${ }^{12}$ T. Obata, H. Hirayama, Y. Aoyagi, and K. Ishibashi, Phys. Status Solidi A 201, 2803 (2004).

${ }^{13}$ S. R. Jeon, Z. Ren, G. Cui, J. Su, M. Gherasimova, J. Han, H. K. Cho, and L. Zhou, Appl. Phys. Lett. 86, 082107 (2005).

${ }^{14}$ H. Yu, W. Strupinski, S. Butun, and E. Ozbay, Phys. Status Solidi A 5, 868 (2006).

${ }^{15}$ A. Chakraborty, C. G. Moe, Y. Wu, T. Mates, S. Keller, J. S. Speck, S. P. DenBaars, and U. K. Mishra, J. Appl. Phys. 101, 053717 (2007).

${ }^{16}$ K. B. Nam, M. L. Nakarmi, J. Y. Lin, and H. X. Jiang, Appl. Phys. Lett. 83, 878 (2003)

${ }^{17}$ M. L. Nakarmi, N. Nepal, C. Ugolini, T. M. Altahtamouni, J. Y. Lin, and H. X. Jiang, Appl. Phys. Lett. 89, 152120 (2006).

${ }^{18}$ C. Stampfl and C. G. Van de Walle, Phys. Rev. B 65, 155212 (2003).

${ }^{19}$ C. G. Van de Walle and J. Neugebauer, J. Appl. Phys. 95, 3851 (2004).

${ }^{20}$ F. Shahedipour and B. W. Wessels, Appl. Phys. Lett. 76, 3011 (2000).

${ }^{21}$ U. Kaufmann, M. Kunzer, M. Maier, H. Obloh, A. Ramakrishnan, B. Santic, and P. Schlotter, Appl. Phys. Lett. 72, 1326 (1998).

${ }^{22}$ U. Kaufmann, M. Kunzer, H. Obloh, M. Maier, Ch. Manz, A. Ramakrishnan, and B. Santic, Phys. Rev. B 59, 5561 (1999).

${ }^{23}$ Y. H. Kwon, S. K. Shee, G. H. Gainer, G. H. Park, S. J. Hwang, and J. J. Song, Appl. Phys. Lett. 76, 840 (2000).

${ }^{24}$ M. A. Reshchikov, G.-C. Yi, and B. W. Wessels, Phys. Rev. B 59, 13176 (1999).

${ }^{25}$ F. Shahedipour and B. W. Wessels, MRS Internet J. Nitride Semicond. Res. 6, 12 (2001).

${ }^{26}$ K. B. Nam, M. L. Nakarmi, J. Y. Lin, and H. X. Jiang, Appl. Phys. Lett. 86, 222108 (2005).

${ }^{27}$ N. Nepal, M. L. Nakarmi, J. Y. Lin, and H. X. Jiang, Appl. Phys. Lett. 89, 092107 (2006).

${ }^{28}$ T. L. Tansley and R. J. Egan, Phys. Rev. B 45, 10942 (1992). 